\title{
Faktor yang Mempengaruhi Pemahaman Kepala Ruang Rawat Inap tentang Pelaporan Kinerja Utilitas Bangsal di Rumah Sakit
}

\section{Factors Influencing the Understanding of Inpatient Ward Manager about Ward Utility Indicator Report at Hospital}

\author{
Riskiyah ${ }^{1}$, Tatong Harijanto ${ }^{2}$, Viva Maiga Mahliafa $\mathrm{N}^{3}$ \\ ${ }^{1}$ Universitas Islam Negeri Maulana Malik Ibrahim Malang \\ ${ }^{2}$ Program Studi Magister Manajemen Rumah Sakit Fakultas Kedokteran Universitas Brawijaya Malang \\ ${ }^{3}$ Rumah Sakit Universitas Muhammadiyah Malang
}

\begin{abstract}
ABSTRAK
Pelaporan kinerja rawat inap merupakan komponen penting dalam evaluasi dan perencanaan rumah sakit. Studi pendahuluan menunjukkan rendahnya kinerja pelaporan rawat inap oleh kepala ruang karena lemahnya pemahanan tentang cara penghitungan dan pelaporan indikator kinerja rumah sakit. Tujuan dari penelitian ini adalah mencari faktorfaktor yang mempengaruhi pemahaman kepala ruang rawat inap dalam menghitung dan melaporkan indikator kinerja efisiensi ruang, mengidentifikasi solusi dan evaluasi dampak solusi tersebut. Metode yang digunakan dalam penelitian ini adalah deskriptif kualitatif dengan melakukan wawancara tidak terstruktur kepada kepala bidang keperawatan, 5 kepala ruang serta 3 perawat di rawat inap. Hasil penelitian menunjukkan bahwa kepala ruang rawat inap tidak mengetahui apa saja indikator efisiensi rumah sakit dan definisinya, perhitungan kinerja bangsal tidak terdeskripsikan dalam Tupoksi (Tugas Pokok dan Fungsi) kepala ruang, tidak ada panduan cara menghitung indikator efisiensi rumah sakit khususnya BOR (Bed Occupancy Rate) di unit rawat inap, belum ada kebijakan dari rumah sakit untuk kepala ruang rawat inap melaporkan kinerja efisiensi ruangan perbulan/pertahun, belum ada sosialisasi dan pelatihan, tidak adanya evaluasi kinerja manajemen bangsal setiap bulan dari rumah sakit. Alternatif solusi yang dipilih rumah sakit untuk mengatasi semua penyebab adalah sosialisasi dan pelatihan tentang perhitungan indikator kinerja ruang kepada petugas rumah sakit. Dampak dari sosialisasi tersebut adalah para kepala ruangan dapat menghitung dan melaporkan indikator kinerja efisiensi dimasing-masing ruangan. Dapat disimpulkan lemahnya pemahaman kepala ruang tentang indikator kinerja karena tidak adanya pelatihan dan panduan yang disebabkan tidak ada dukungan kebijakan dan anggaran.
\end{abstract}

Kata Kunci: Indikator efisiensi rumah sakit, kepala ruang, pemahaman, rawat inap

\begin{abstract}
Inpatient ward utility indicator report is an important component in hospital's evaluation and planning. Preliminary studies showed low reporting performance by inpatient ward manager due to low understanding on how to count and report the hospital performance indicators. The purpose of this study is to find the factors that influence the inpatient ward manager understanding in calculating and reporting the ward efficiency performance indicators, identifying solutions, and evaluating the solutions' impact. The method used in this research was descriptive qualitative by conducting unstructured interviews to the head of nursing, 5 ward managers, and 3 nurses on inpatient unit. The results showed that the ward managers did not know what were the hospital's efficiency indicators and the definition, the calculation of wards' performance was not described in ward manager's Main Duties and Functions, no guidance on how to calculate hospital efficiency indicator especially BOR (Bed Occupancy Rate) in inpatient units, no hospital policy for inpatient ward manager to report monthly/yearly on performance efficiency, no socialization and training, lack of monthly wards' management performance evaluation from the hospital. Alternative solutions selected to address all causes were dissemination and training on room performance indicator calculation to hospital employees. The impact of this socialization was that the ward managers could calculate and report the efficiency performance indicator. It can be concluded the lack of understanding of the performance indicators was due to lack of training and guidance which were caused by no supporting policy and budget.
\end{abstract}

Keywords: Hospital efficiency indicators, inpatient unit, ward manager, understanding

Korespondensi: Riskiyah. Universitas Islam Negeri Maulana Malik Ibrahim Malang, Jl. Gajayana No. 50 Malang Jawa Timur Tel. 081938695478Email:riskiyah_cute@ymail.com 


\section{PENDAHULUAN}

Pelaporan yang dilakukan rumah sakit merupakan suatu alat yang bertujuan untuk menghasilkan laporan yang cepat, tepat serta dapat dipercaya guna berbagai keperluan pengelolaan rumah sakit. Dalam menulis pelaporan rumah sakit dengan baik, pengelola perlu memahami statistik rumah sakit sehingga data bisa didapatkan secara benar dan akurat. Statistik rumah sakit adalah suatu statistik yang menggunakan dan mengolah sumber data dari berbagai pelayanan kesehatan di rumah sakit untuk menghasilkan berbagai sumber informasi, fakta, dan pengetahuan yang berkaitan dengan pelayanan kesehatan di rumah sakit (1). Salah satu kegiatan yang rutin dilakukan dalam statistik rumah sakit adalah menghitung tingkat efisiensi hunian tempat tidur (TT). Perhitungan ini dilakukan untuk memantau aktivitas penggunaan tempat tidur di unit instalasi rawat inap dan digunakan sebagai rencana dalam pengembangannya (2). Parameter kinerja yang dibutuhkan untuk menentukan tempat tidur yang tersedia telah efektif dan efisien salah satunya menggunakan BOR (bed occupancy rate).

Kepala ruang merupakan manajer lini pertama dalam rumah sakit yang akan menggerakkan staf dalam mencapai tujuan rumah sakit. Manajer lini pertama ini mempunyai peran dan fungsi manajerial yang berbeda dengan manajer lain yang lebih tinggi atau sejajar dengannya (3). Kepala ruang adalah manajer operasional yang merupakan pimpinan yang secara langsung mengelola seluruh sumber daya di unit perawatan dan ikut bertanggungjawab dalam menghasilkan pelayanan yang bermutu (4). Kepala ruang merupakan jabatan yang cukup penting dan strategis, karena secara manajerial kemampuan kepala ruang ikut menentukan keberhasilan pelayanan keperawatan (4). Seorang kepala ruang unit rawat inap berperan sebagai manajer keperawatan di ruangan diharapkan mampu melaksanakan fungsi perencanaan, pengorganisasian dan pengarahan serta pengawasan. Selain itu kepala ruang dapat memadukan berbagai kegiatan pelayanan di ruang rawat inap baik perawatan maupun medis serta kegiatan penunjang lainnya sesuai kebutuhan pasien (5).

Tiap bulan kepala ruangan rawat inap di RS UMM hanya melaporkan jumlah pasien, jumlah kasus baik medis (misal 10 penyakit terbanyak) maupun non medis (misal tentang kebersihan, fasilitas di ruangan jika ada yang rusak), jumlah pasien yang dirujuk keluar, jumlah pasien meninggal, jumlah pasien yang dilakukan pemeriksaan laboratorium, absensi dan kedisiplinan para perawat ruangan serta komplain dari pasien maupun keluarganya kepada kepala bidang keperawatan. Kepala ruangan tidak pernah memberikan laporan tentang pencatatan sensus harian rawat inap kepada petugas rekam medis.

Dalam pengelolaan Unit Rawat Inap (URI), salah satu aspek yang perlu diperhatikan adalah pengelolaan tempat tidur pasien. Pengelolaan tempat tidur pasien perlu mendapat perhatian besar dari manajemen rumah sakit karena sebagai tempat perawatan pasien, yang perlu dikelola dengan baik guna memperoleh efisiensi dalam penggunaan. Evaluasi dapat dilakukan dengan relokasi tempat tidur yaitu dengan mengurangi tempat tidur pada bangsal yang okupansinya rendah, dipindah ke bangsal yang tingkat penggunaannya tinggi, bahkan cenderung over load, atau menutupnya bahkan mengganti pelayanan lain yang lebih efisien dan menguntungkan (6).
Hasil studi pendahuluan menunjukkan beberapa permasalahan yang saat ini dihadapi oleh RS UMM salah satunya adalah pencapaian BOR yang masih rendah yang berarti inefisiensi penggunaan bangsal rawat inap belum sesuai dengan nilai ideal dari Departemen Kesehatan (Tabel 1). Tingkat BOR yang rendah ini menandakan bahwa RS.UMM belum begitu banyak di kunjungi oleh masyarakat yang datang untuk di rawat inap di RS UMM. Jika angka kunjungan rawat inap masih rendah hal ini akan mempengaruhi pendapatan dari rumah sakit. Tingkat hunian atau BOR bisa dipengaruhi oleh berbagai faktor antara lain faktor internal dan faktor eksternal rumah sakit. Faktor internal adalah budaya rumah sakit, sistem nilai, kepemimpinan, sistem manajemen, sistem informasi, sarana prasarana, sumber daya manusia, pemasaran, citra, dan lain-lain. Faktor eksternal adalah letak geografis, keadaan sosial ekonomi konsumen, budaya masyarakat, pemasok, pesaing, kebijakan pemerintah daerah, peraturan, dan lain-lain (7).

Tabel 1. Data efisiensi dan mutu pengelolaan RS UMM Tahun 2013-2015 (bulan Juli)

\begin{tabular}{|c|c|c|c|c|}
\hline \multirow[b]{2}{*}{ Uraian } & \multicolumn{3}{|c|}{ Tahun } & \multirow{2}{*}{$\begin{array}{l}\text { Indikator } \\
\text { Efisiensi }\end{array}$} \\
\hline & 2013 & 2014 & $\begin{array}{c}2015 \\
\text { (JULI) }\end{array}$ & \\
\hline BOR RS (\%) & $15 \%$ & $15 \%$ & $19 \%$ & $60-85 \%$ \\
\hline TOI (hari) & 16 hari & 16 hari & 51 hari & 1-3 hari \\
\hline BTO (kali) & 17 kali & 17 kali & 1 kali & $40-50$ kali \\
\hline ALOS (hari) & 4 hari & 4 hari & 3 hari & 6-9 hari \\
\hline GDR (\%) & 0 & 0 & 0 & $\leq 45$ \\
\hline NDR (\%) & 0 & 0 & 0 & $<25$ \\
\hline
\end{tabular}

Sumber: Laporan tahunan RS UMM, 2015 (Data didapat dari petugas IT kemudian diolah oleh petugas rekam medis)

Hasil telusur peneliti melalui wawancara kepada kepala keperawatan, kepala rawat inap, kepala rekam medis, pihak manajemen rumah sakit serta dari hasil studi dokumen di RS UMM ditemukan bahwa salah satu faktor penyebab BOR yang rendah adalah dari segi sistem manajemen internal bangsal. Pada manajemen internal bangsal didapatkan bahwa manajer bangsal (kepala ruang) tidak pernah melaksanakan analisis harian dan bulanan sendiri terutama mereka tidak paham tentang cara perhitungan BOR dan indikator efisiensi rumah sakit lainnya (ALOS, TOI, GDR, NDR, BTO). Data laporan BOR tiap bulan dari masing-masing ruangan rawat inap di RS UMM tidak di dapatkan dari kepala ruangan unit rawat inap tetapi didapatkan dari petugas rekam medis. Petugas rekam medis mendapatkan data jumlah pasien rawat inap dari petugas IT (Information Technology) rumah sakit kemudian petugas rekam medis ini mengolah data yang didapat dan menghitung pencapaian BOR di tiap-tiap ruangan rawat inap. Data yang didapat dari petugas IT tentang jumlah pasien rawat inap bisa saja salah karena sistem eror dari komputer atau petugas rawat inap tidak segera melaporkan ke petugas IT jika ada perubahan status pasien, oleh karena itu penting bagi kepala ruangan rawat inap paham tentang perhitungan BOR sebagai indikator utilitas sehingga data yang dihasilkan bisa lebih akurat. Kepala ruangan merupakan orang yang paling tahu kondisi di lapangan tentang utilitas dari tempat tidur di rawat inap bukan petugas IT maupun petugas rekam medis. Berdasarkan latar belakang diatas, tujuan penelitian ini adalah mencari faktor-faktor yang 
mempengaruhi pemahaman manajer bangsal (kepala ruang) unit rawat inap tentang pelaporan kinerja efisiensi bangsal dan mengembangkan solusi serta mengevaluasi dampak solusi tersebut.

\section{METODE}

Penelitian ini dilakukan dengan metode deskriptif kualitatif. Cara pengambilan data adalah dengan wawancara tidak terstruktur. Wawancara dilakukan pada tanggal 2-3 Oktober 2015 kepada 3 petugas rawat inap, 5 kepala ruang rawat inap dan 1 kepala bidang keperawatan. Pemilihan 9 informan tersebut karena dianggap sudah mewakili bagian ruang rawat inap untuk menggali lebih dalam dan mencari faktor-faktor penyebab yang mempengaruhi ketidakpahaman kepala ruangan dalam menghitung BOR yang direkam menggunakan alat perekam. Aspek yang ditanyakan pada wawancara berhubungan dengan man (manusia), machine (mesin), management (manajemen), material, methode (metode) dan money (uang) yang diadaptasi dari fish-bone Ishikawa kemudian dilakukan analisis akar masalahnya dengan metode 5 why's. Berdasarkan akar masalah disusun beberapa alternatif solusi terhadap permasalahan secara brainstorming dengan pihak manajemen RS UMM.

\section{HASIL}

Faktor yang Mempengaruhi Pemahaman Kepala Ruang dalam Pelaporan Kinerja Utilitas Bangsal (BOR)

Hasil wawancara menunjukkan lemahnya pemahaman kepala ruang maupun petugas tentang penghitungan BOR sebagai salah satu indikator kinerja utilitas yang penting di bangsal, sebagaimana ditunjukkan pada kutipan wawancara berikut:

"Para petugase gak ngerti mbak, Aku aja ngak ngerti mbak rumus BOR itu apa, gimana bisa ngitung" (T031015)

"Kayaknya sih karena kita gak bisa ngitungnya dok, karena saya juga tidak tahu rumus BOR itu, definisinya juga gak tau" (1021015)

"Indikator rumah sakit aja cuman tahunya BOR, ALOS yang lain gak tau" (S021015)

Lemahnya pemahaman tersebut salah satunya karena tidak ada rasa bertanggungjawab atau menganggap bahwa penghitungan dan pelaporan kinerja bukan merupakan tanggungjawab kepala ruang. Kondisi tersebut juga diperkuat dengan tidak adanya kebijakan yang mengatur pelaporan BOR ruang rawat inap

"Kalo menghitung BOR itu kan bukan tugas kita mbak, lagian kita gak tahu ngitungnya gimana" (L021015)

"Kita tidak pernah melaporkan pencapaian BOR dari ruangan mbak, kan yang ngitung petugas RM" (M021015)

"Belum ada kebijakannya mbak dari direktur kalo kita harus melaporkan BOR tiap bulan jadinya yang ngitung BOR petugas rekam medisnya" (L021015)

"Tidak pernah ada evaluasi dari pihak rumah sakit untuk hasil BOR tiap bulannya, jadinya ya kita gak pernah menghitung BOR ruangan mbak" (Li021015)

Faktor lain yang berkontribusi terhadap kurangnya pemahaman tersebut juga karena tidak adanya pelatihan atau sosialisasi, karena tidak ada alokasi khusus anggaran, serta ketika harus menghitung tidak ada pedoman yang dapat digunakan sebagai acuan.

"Belum pernah ada mbak sosialisasi maupun pelatihan tentang menghitung BOR 'Itu'" (Li021015)

"Lah rumah sakit emang tidak pernah ada anggaran untuk mengadakan pelatihan tentang menghitur BOR mbak" (T031015)

"Gak ada dari rumah sakit panduan bagaimana sih cara menghitung BOR" (T031015)

Apabila dikaji tema yang muncul menggambarkan sumber permasalahan mulai dari faktor struktur (kebijakan), proses dan sarana pada pross hingga berujung pada lemahnya pemahaman kepala ruang tengang penghitungan kinerja efisiensi ruangan. Berdasarkan pengelompokan tersebut mengerucut akar masalah dan dapat diidentifikasi pilihan solusi masing-masing. Secara keseluruhan akar masalah pada struktur dan kebijakan yaitu tidak adanya kebijakan tentang pengukuran kinerja efisiensi masing-masing ruang yang juga mengatur tentang peran dan tanggungjawab pelaporan, menjadi penyebab mendasar sehingga tidak ada alokasi anggaran untuk peningkatan pemahaman petugas dan kepala ruang, tidak ada panduan dan pedoman penghitungan sehingga pada akhirnya menyebabkan rendahnya pemahaman dan kurangnya kinerja pelaporan.

Tabel 2. Analisis akar masalah dan identifikasi solusi

\begin{tabular}{lll}
\hline \multicolumn{1}{c}{$\begin{array}{c}\text { Letak } \\
\text { Masalah }\end{array}$} & \multicolumn{1}{c}{ Akar Masalah } & \multicolumn{1}{c}{ Solusi } \\
\hline $\begin{array}{l}\text { Struktur } \\
\text { (Kebijakan) }\end{array}$ & $\begin{array}{l}\text { Tidak ada kebijakan } \\
\text { pelaporan kinerja } \\
\text { efisiensi ruang }\end{array}$ & $\begin{array}{l}\text { Perumusan dan } \\
\text { kesepakatan kebijakan } \\
\text { pelaporan kinerja efiseiensi }\end{array}$ \\
& $\begin{array}{l}\text { Tidak ada alokasi } \\
\text { anggaran }\end{array}$ & Pengalokasian anggaran \\
& $\begin{array}{l}\text { Tidak ada sosialisasi } \\
\text { dan pelatihan }\end{array}$ & Sosialisai dan pelatihan \\
Proses, & $\begin{array}{l}\text { Tidak ada panduan dan } \\
\text { pedoman } \\
\text { Sarana }\end{array}$ & $\begin{array}{l}\text { Pengembangan buku } \\
\text { pedoman dan panduan } \\
\text { penghitungan dan } \\
\text { pelaporan }\end{array}$ \\
Output & $\begin{array}{l}\text { Lemahnya pemahaman } \\
\text { cara penghitungan } \\
\text { kinerja dan } \\
\text { tanggungjawab } \\
\text { pelaporan }\end{array}$ & $\begin{array}{l}\text { Monitoring dan evaluasi } \\
\text { pelaporan kinerja efisiensi } \\
\text { ruang }\end{array}$ \\
\hline
\end{tabular}

Berdasarkan analisis akar masalah tersebut alternatif solusi yang ditawarkan oleh peneliti kepada Rumah Sakit Universitas Muhammadiyah Malang menyangkut ketidakpahaman kepala ruang menghitung BOR antara lain pertama, membuat kebijakan tentang perhitungan BOR di tiap ruangan. Solusi yang kedua adalah membuat panduan pencatatan dan cara menghitung BOR. Solusi yang ketiga adalah sosialisasi dan pelatihan tentang cara perhitungan BOR. Solusi yang keempat adalah membuat laporan BOR dan indikator efisiensi rumah sakit lainnya tiap bulan dari masing-masing ruangan. Solusi yang kelima adalah evaluasi BOR tiap bulan dari masing-masing ruangan. 
Alternatif solusi yang diberikan oleh peneliti kemudian dilakukan brainstorming dengan pihak manajemen RS UMM. Pihak manajemen rumah sakit memutuskan solusi yang dipilih untuk dilakukan oleh peneliti adalah sosialisasi dan pelatihan tentang perhitungan BOR kepada petugas RS UMM khususnya kepala ruang rawat inap. Nantinya diharapkan tiap bulan kepala ruangan bisa memberikan laporan tentang BOR dan indikator efisiensi rumah sakit lainnya kemudian mengadakan evaluasi serta membuatkan panduan cara menghitung BOR dan indikator efisiensi rumah sakit lainnya.

\section{Intervensi dan Dampak Intervensi}

Pada tanggal 26 Oktober 2016 peneliti melakukan sosialisasi dan pelatihan yang dihadiri oleh 15 orang antara lain 1 kepala bidang keperawatan, 6 kepala ruangan unit rawat inap dan sisanya para perawat ruangan rumah sakit. Materi yang disampaikan meliputi indikator efisiensi rumah sakit tidak hanya BOR tetapi juga ALOS (Average Length Of Stay), BTO (Bed Turn Over), TOI (Turn Over Interval), GDR (Gross Death Rate), NDR (Net Death Rate) serta bagaimana merekap data pasien dalam 1 bulan sehingga memudahkan dalam proses perhitungan indikator efisiensi rumah sakit. Peneliti juga membagikan kepada peserta panduan tentang menghitung BOR dan indikator efisiensi rumah sakit lainnya yang dapat digunakan mereka sebagai pegangan. Pelatihan dilakukan dengan membahas kasus pada pre-test dan latihan soal atau praktek penghitungan indikator kinerja rumah sakit.

Hasil pelatihan dari nilai post test $53 \%$ menjawab dengan benar namun masih terdapat $47 \%$ menjawab salah. Disamping perbaikan pemahanman, pada bulan selanjutnya para kepala ruangan sudah bisa menghitung BOR ruangan mereka masing-masing dan memberikan laporan pencapaian BOR kepada petugas rekam medis dan kepala keperawatan. Selain itu kepala ruang juga sudah bisa melakukan analisis harian dan bulanan masingmasing ruang.

\section{DISKUSI}

Hasil penelitian menunjukkan bahwa penyebab ketidakpahaman kepala ruang dalam menghitung dan melaporkan kinerja efisiensi RS adalah mereka tidak mengetahui cara menghitung dan rumus penghitungan indikator efisiensi. Penyebab lain adalah belum pernah ada sosialisasi serta pelatihan tentang perhitungan indikator tersebut terutama BOR berdasarkan data rekam medis sehingga pengetahuan kepala ruang rawat inap tentang perhitungan indikator efisiensi rumah sakit khususnya BOR masih minim. Penelitian Handiyani dkk juga menemukan lemahnya sosialisasi dan tidak adanya panduan teknis pengendalian infeksi nosokomian disetiap ruang menjadi penyebab ketidakberhasilan kegiatan pengendalian infeksi dari segi proses penerapan peran informasional dan decisional kepala ruang rawat inap (8).

Selain itu penyebab ketidakpahaman kepala ruang dalam menghitung indikator kinerja efisiensi ruang adalah belum adanya kebijakan tentang pelaporan dan evaluasi BOR dari masing-masing ruangan untuk tiap bulannya. Padahal adanya kebijakan ini sangat penting agar timbul tanggung jawab dan merubah perilaku para kepala ruang agar mereka selalu memberikan laporan kienrja efisiensi ruang. Kebijakan RS adalah penetapan Direktur/Pimpinan RS pada tataran strategis atau bersifat garis besar yang mengikat (9). Jika ada kebijakan dari rumah sakit tentang pelaporan kinerja efisiensi bagi kepala ruang rawat inap akan membuat perubahan perilaku kepala ruangan karena mereka akan lebih memahami tugasnya dan membuat mereka untuk lebih belajar tentang indikator efisiensi rumah sakit serta cara menghitungnya. Hal ini sesuai dengan hasil penelitian yang dilakukan oleh Semuel bahwa terdapat pengaruh positif kebijakan terhadap perilaku kerja individu dan sistem organisasi (10). Kebijakan dibuat berdasarkan teori dan proposisi-proposisi sebab akibat. Oleh karena itu, kebijakan hendaknya bersandar pada asumsi-asumsi mengenai prilaku. Hal ini penting agar kebijakan selalu mendorong orang untuk melakukan sesuatu, serta mampu memprediksi keadaan dan menyatukan perkiraan-perkiraan mengenai keberhasilan yang akan dicapai dengan mekanisme mengatasi kegagalan yang mungkin terjadi (11).

Hasil pelatihan pada penelitian ini menunjukkan perbaikan pemahaman dan kinerja pelaporan. Menurut Wicaksono pelatihan dapat mempengaruhi kinerja karyawan (12). Hal ini sesuai dengan penelitian oleh Mustariningrum dkk yang mengidentifikasi bahwa pelatihan program PPI Dasar kepada seluruh IPCLN termasuk dalam kategori tinggi pencapaiannya (rerata 3,78) dengan indikator pengetahuan memberikan kontribusi tertinggi (13).

Pelatihan yang semakin baik maka akan memberikan peningkatan terhadap kinerja karyawan yang lebih baik pula. Maka penting bagi rumah sakit untuk selalu melakukan sosialisasi dan pelatihan agar meningkatkan pengetahuan kepala ruangan. Sosialisasi tentang indikator efisiensi rumah sakit khususnya BOR dan pelatihan perhitungan BOR ini sangat berguna bagi kepala ruangan unit rawat inap menambah wawasan dan pengetahuan mereka. Pelatihan sumber daya manusia disetiap organisasi sangat dibutuhkan agar organisasi tetap bertahan dan dapat membantu dalam memenangkan competitive advantage untuk sumber daya manusia yang tidak dapat dicontoh. Program pelatihan dan pengembangan bagi pegawai rumah sakit dapat berperan sebagai pendorong utama pelaksanaan kegiatan strategis. Pelatihan (training) merupakan proses pembelajaran yang melibatkan perolehan keahlian, konsep, peraturan, atau sikap untuk meningkatkan kinerja pegawai $(14,15)$.

Sosialisasi adalah pendekatan yang didasarkan atas perbedaan masyarakat sasaran. Dengan kata lain, sosialisasi merupakan bentuk upaya menyebarluaskan informasi kepada orang banyak dalam hal ini adalah kepala ruang rawat inap dan petugas rawat inap. Hal itu dimaksudkan agar kepala ruang dan petugas rawat inap dapat menerima dan memahami isi dari informasi tersebut. Pada sisi teknisnya, sosialisasi dapat dilakukan dengan beragam model atau cara agar sosialisasi tersebut berjalan sesuai dengan harapan dan seefektif mungkin (16).

Kajian ini menunjukkan bahwa kurang adekuatnya kinerja pelaporan indikator efisiensi rumah sakit yang disebabkan oleh kurangnya pemahaman kepala ruang mempunyai sebab yang mendasar yaitu tidak adanya kebijakan dan alokasi anggaran sehingga tidak ada program pelatihan maupun sosialisasi. Sosialisasi dan pelatihan yang dilakukan dalam jangka pendek terbukti dapat memperbaiki pemahaman dan praktek pelaporan, namun dalam jangka panjang perlu didukung kebijakan dan evaluasi berkelanjutan 


\section{DAFTAR PUSTAKA}

1. Dwianto dan Lestari T. Analisis Efisiensi Pelayanan Rawat Inap Berdasarkan Grafik Barber Johnson pada Bangsal Kelas III di RSUD Pandan Arang Boyolali Periode Triwulan Tahun 2012. Jurnal Manajemen Informasi Kesehatan Indonesia. 2013; 1(2): 70-78.

2. Lestari T. Analisis Penggunaan Tempat Tidur Berdasarkan Grafik Baber Johnson Perbulan Tahun 2012 untuk Memenuhi Standar Mutu Pelayanan Rawat Inap di RS Pku Muhammadiyah Sukoharjo. Jurnal Ilmiah Rekam Medis dan Informatika Kesehatan. 2013;3(1): 1-11.

3. Pratiwi A dan Utami YW. Pembinaan dan Pendampingan Pimpinanan Keperawatan dalam Melaksanakan Peran dan Fungsi Manajemen pada Kepala Ruang di RS PKU Muhammadiyah Surakarta. Warta. 2010; 13(1): 37-47.

4. Wahyuni S. Analisis Kompetensi Kepala Ruang dalam Pelaksanaan Standar Manajemen Pelayanan Keperawatan dan Pengaruhnya Terhadap Kinerja Perawat dalam Mengimplementasikan Model Praktik Keperawatan Profesional Di Instalasi Rawat Inap RSUD Banjarnegara. [Tesis]. Universitas Diponegoro, Semarang. 2007.

5. Nursyamsi AA. Hubungan Fungsi Manajemen Kepala Ruangan Dengan Tugas Kepala Ruangan Rawat Inap di Rumah Sakit Umum Daerah Haji Padjonga Daeng Ngalle Kabupaten Takalar. Jurnal IImiah Kesehatan Diagnosis. 2014; 5(3).

6. Indriani $\mathrm{P}$ dan Sugiarti I. Gambaran Effisiensi Penggunaan Tempat Tidur Ruang Perawatan Kelas III di Rumah Sakit Umum Daerah Tasikmalaya Tahun 2011 dan 2012. Jurnal Manajemen Informasi Kesehatan Indonesia. 2014; 2(1): 68-73.

7. Susanto H. Analisis Faktor-faktor yang Mempengaruhi Bed Occupancy Rate (BOR) Rumah Sakit" Roemani" Semarang. [Tesis]. Universitas
Diponegoro, Semarang. 1999.

8. Handiyani H, Allenidekania, dan Eryando, T. Hubungan Peran dan Fungsi Manajemen Kepala Ruangan dengan Keberhasilan Pelaksanaan ProgramPengendalian Infeksi Nosokomial. Jurnal Keperawatan Indonesia. 2004; 8(2): 54-61.

9. Semuel H. Penerapan Kebijakan Penggunaan Energi Listrik terhadap Kinerja Usaha Mikro Kecil dan Menengah di Provinsi Jawa Timur. Jurnal Manajemen Pemasaran. 2014; 8(1): 39-46

10. Bakry A. Kebijakan Pendidikan sebagai Kebijakan Publik. Jurnal Media Edukasi Pendidikan Teknologi dan Kejuruan. 2010; 2(1): 13.

11. Wicaksono YS. Pengaruh Pelatihan dan Pengembangan Sumber Daya Manusia dalam Rangka Meningkatkan Semangat Kerja dan Kinerja Karyawan (Studi di SKM Unit V PT. Gudang Garam, Tbk Kediri). Jurnal Bisnis dan Manajemen. 2016; 3(1): 31-39.

12. Mustariningrum DLT, Koeswo M, dan Ahsan. Kinerja IPCLN dalam Pencegahan dan Pengendalian Infeksi di Rumah Sakit: Peran Pelatihan, Motivasi Kerja dan Supervisi. Jurnal Aplikasi Manajemen. 2015; 13(4): 643-652.

13. Baharuddin A, Alhabsyi T, dan Utami HN. Pengaruh Pelatihan, Kompensasi, dan Disiplin Kerja terhadap Prestasi Kerja Karyawan (Studi Pada Kantor PT. PLN (Persero) Area Pelayanan dan Jaringan Malang). Profit-Jurnal Administrasi Bisnis. 2013;6(2): 56-68.

14. Yulianti E, Juliati L, dan Nala IWL. Pengaruh Pelatihan terhadap Kinerja Karyawan Grand Fatma Hotel di Tenggarong Kutai Kartanegara. eJurnal Administrasi Bisnis. 2015; 3(4): 900-910.

15. Susanti E. Evaluasi Sosialisasi Peraturan Daerah Samarinda No. 02 Tahun 2011 Pasal 38 Poin 8 tentang Larangan Waktu Membuang Sampah di Kelurahan Sempaja Utara. eJournal IImu Komunikas. 2014; 2(2): 49-62. 